\title{
El principio de culpabilidad como garantía para los empleados públicos en los procesos disciplinarios
}

\author{
The principle of guilt as a guarantee for public employees \\ undergoing disciplinary processes
}

\author{
Ronald A. Euseda-Aguilar \\ eusedalaw@gmail.com \\ Recibido: 11/04/18 - Aceptado: 12/05/18
}

URI: http://hdl.handle.net/11298/453

DOI: http://dx.doi.org/10.5377/entorno.v0i65.6050

\section{Resumen}

El régimen disciplinario de los empleados públicos no cuenta con un ordenamiento común que regule las garantías constitucionales, especialmente el principio de culpabilidad. Ante la dispersión de normas jurídicas y la no regulación de principios constitucionales, se vuelve necesario exponer cómo es que este principio, a pesar de ese panorama oscuro, logra brillar para proteger a los empleados públicos ante los procesos disciplinarios a los que se enfrentan.

El propósito de la presente investigación teórica es presentar la construcción teórico-abstracta de las garantías que implica el principio de culpabilidad, y su aplicación en los regímenes disciplinarios; para ello,

\section{Abstract}

The disciplinary regime of public employees lacks a common code to regulate constitutional guarantees, especially the principle of guilt. In the face of the dispersion of legal norms and the non-regulation of constitutional principles, it becomes necessary to show how it is that this principle, in spite of such an obscure panorama, manages to shine in order to protect public employees facing disciplinary processes.

The purpose of this theoretical investigation is to present the theoretical-abstract construction of the guarantees that the principle of guilt implies, and its application in disciplinary regimes; in order to do so, we have revised the doctrine that generated around it; in like manner, the

Docente de Derecho Administrativo y Mercantil de la Universidad Tecnológica de El Salvador. Abogado, Notario y Árbitro. Licenciado en Ciencias Jurídicas por la Universidad de El Salvador, Máster en Estudios Judiciales impartida en conjunto con la Universidad Católica de El Salvador, la Universidad Doctor José Matías Delgado y la Escuela Superior de Economía y Negocios, con diplomaturas en Derecho Procesal Civil y Mercantil, Derecho Aduanero, Criminalística y Medicina Legal, Investigación Jurídica y Métodos de Resolución Alterna de Conflictos. 
hemos revisado la doctrina que se ha generado en torno a este, así mismo, la jurisprudencia constitucional y su adaptación a nuestro sistema jurídico.

\section{Palabras clave}

Funcionarios públicos. Salud pública - Legislación. Administración pública. Culpa jurídica. Responsabilidad penal. constitutional law and its adaptation to our legal system has also been revised.

\section{Keywords}

Public officers. Public health-Legislation. Public administration. Legal guilt. Criminal responsibility.

\section{Introducción}

Nuestra administración pública no cuenta con una ley de procedimientos administrativos, eso produce una dispersión de normas que regulan cada institución y su sistema disciplinario para los empleados públicos, no existiendo uniformidad para el régimen disciplinario. Es por eso cada empleado debe estar atento a la norma que regule su actuar y esperar que dicha norma sea benevolente y regule todos los principios que le den garantía a su proceso. Pero es el caso que en nuestro sistema la mayoría de normas jurídicas que regulan un orden disciplinario no regulan dichos principios y garantías, especialmente el principio de culpabilidad. Eso deja a los empleados públicos en un estado de inseguridad jurídica, dado que en sede administrativa no podrá alegar dichos principios, a menos que la autoridad que juzgue sea versada y respete las garantías constitucionales, de lo contrario tendrá que esperar a llegar al área judicial para realizar un mejor reclamo basado en Derecho.

Una de las principales garantías es el principio de culpabilidad, del cual se predica ser uno de los pilares de toda la actividad sancionadora del Estado, como la penal y la administrativa, incluyendo la civil. Es así que dicho principio no puede verse ignorado en ninguna de estas actividades. Para el caso en específico, el principio de culpabilidad está reconocido en el artículo 12 de nuestra Carta Magna, y establece que "toda persona a quien se impute un delito, se presumirá inocente mientras no se pruebe su culpabilidad conforme a la ley y en juicio público, en el que se le aseguren todas las garantías necesarias para su defensa". ${ }^{2}$

Dicho reconocimiento se predicó de modo exclusivo para el área penal, sin embargo, la Sala de lo Constitucional, mediante la Sentencia de Inconstitucionalidad de Ref. 3-92 (AC) 6-92 del 17-12-1992, ha marcado las fronteras entre la era de la responsabilidad objetiva y subjetiva en el ámbito administrativo sancionador. ${ }^{3}$ Es así como se cambia el paradigma de la permisibilidad de la responsabilidad objetiva en el Derecho Administrativo Sancionador. Dentro de los argumentos del Tribunal Constitucional, para llegar a esa conclusión, consta en primer término el reconocimiento de la unidad ontológica entre la ilicitud penal y tributaria entiéndase la tributaria como una especie de ilegalidad administrativa.

Lo que conllevó a que se interpretara el Art. 12 de la $\mathrm{Cn}$. en el sentido siguiente:

.... el vocablo "delito" consignado en el Artículo 12 inciso primero de la Constitución debe entenderse no en sentido estricto, sino como indicativo de un ilícito o injusto típico, esto es, conducta humana que en virtud de mandato legal se haced reprochable a efecto de su sanción; incluyéndose en este concepto a las infracciones administrativas, y específicamente las tributarias. Esta equiparación -que no puede hacerse más que por el rasero de la teoría general del delito- implica que los principios del Derecho

\footnotetext{
2 De la redacción, puede observarse que dicho reconocimiento de la culpabilidad está parcializado a materia penal, al mencionar solo el vocablo delito, situación que se mantuvo así hasta que, vía jurisprudencial, se amplió el espectro de aplicación de dicha disposición.

3 Antes de la asimilación de los principios penales, al Derecho Administrativo Sancionador, la responsabilidad por el cometimiento de una infracción administrativa era objetiva, esta no requería de dolo o culpa en la conducta sancionable... (García de Enterría, Eduardo y Ramón Fernández, Tomás). Curso de Derecho Administrativo, Vol. II. España: Civitas, 2006. p. 181; en la responsabilidad objetiva lo fundamental es la causación de un resultado, sin importar la participación que tuvo el autor en él; lo esencial es la relación de causalidad, sin contemplar la faz subjetiva de la acción... (Edwars, Carlos Enrique. Régimen Penal y Procesal Penal Aduanero. Comentario de los artículos 860 a 1180 de la ley 22.415 con las modificaciones introducidas por las leyes $23.353,24.415$ y el decreto 1684/93. Delitos e Infracciones Aduaneras Procedimientos. Recursos. Buenos Aires: Astrea, 1995... p. 96).
} 
Administrativo sancionatorio son los que se sistematizan en el Derecho Penal de aplicación judicial, en la medida necesaria para preservar los valores esenciales que se encuentran en la base del precepto.

Por lo que concluye diciendo: "Podemos asegurar entonces, sin ambages, que en materia administrativa sancionatoria es aplicable el principio nulla poena sine culpa; lo que excluye cualquier forma de responsabilidad objetiva". ${ }^{4}$

Es importante mencionar que con dicha jurisprudencia también se reconoce la unidad del Ius puniendi del Estado, lo que implica que Derecho Penal y Administrativo Sancionador es solo una manifestación del poder represivo estatal. Lo que trae consigo la teoría de los "matices", mediante la cual se pregona que la aplicación de los principios penales al ámbito administrativo sancionador. Este es el punto medular del presente artículo, que busca desentrañar en qué medida es el principio de culpabilidad garantía para los empleados públicos en el derecho disciplinario. Esto porque se ha dicho que el principio de culpabilidad se aplica en el Derecho Administrativo Sancionador como una consecuencia de la teoría de los "matices", lo que traería como consecuencia una disminución en la exigencia de la aplicación de los principios penales. Parafraseando a Antequera, que nos dice que "...hoy en día se acepta que los principios generales del derecho sancionador son los mismos que rigen en el derecho penal, si bien es cierto que admitiendo ciertos matices, por ser ambos tipos de sanciones manifestaciones del poder punitivo del Estado...Los citados principios se aplican con la máxima rigidez en el ámbito puramente penal, atenuándose en el derecho administrativo sancionador en general hasta llegar a su debilitamiento máximo, o incluso su desaparición" ${ }^{5}$ Sin embargo, existe otra posición que nos dice que el principio de culpabilidad se aplica como una exigencia de Estado Constitucional de Derecho. Es por ello que nos debemos aclarar dicha situación para poder exponer en qué medida el principio de culpabilidad es una garantía en el derecho disciplinario que se les aplica a los empleados públicos. Especialmente con la agravante de que no existe una ley de procedimientos administrativos, ni mucho menos una ley disciplinaria del sector público. Lo que no solo puede llevar a la aplicación de las garantías penales, en el mejor de los casos, sino también a su disminución, y por otro lado, a ser ignorados.

\section{El principio de culpabilidad como exigencia del Estado Constitucional de Derecho o consecuencia de la sujeción a los principios penales (teoría de los matices)}

La aplicación del principio de culpabilidad ha sido asimilada como una consecuencia de la aplicación de los principios penales a materia administrativa, lo que equivaldría a decir que la culpabilidad se aplica en el Derecho Administrativo Sancionador, porque se exige en materia penal, en fin de cuentas, un mero traslado. Ante esta postura, la doctrina no se ha hecho esperar, pregonando que tal conclusión es equivoca. Así la moderna teoría enlaza el concepto de sanción sobre una base constitucional, con el principio de culpabilidad. Para ser más concreto, Cano Campos explica: "El concepto moderno (constitucional) de sanción está indisolublemente unido al principio de culpabilidad, pues de dicho concepto no solo deriva la exigencia de que la Administración castigue respetando el principio de legalidad sino también el de culpabilidad". ${ }^{6}$ Esto por ser la sanción un concepto del Estado de Derecho. Siendo consecuente con esta teoría, manifiesta Huergo Lora que "el principio de culpabilidad es, en un Estado de Derecho, una consecuencia necesaria del concepto de sanción y por tanto debe aplicarse aunque no se acepte la importancia general de los principios del Derecho Penal" ${ }^{\prime 7-8}$

Esta postura ha sido acogida por la jurisprudencia constitucional, desde la Sentencia de Inconstitucionalidad de Ref. 3-92 (AC) 6-92 del 17-12-1992. Por ello, es necesario examinar los argumentos de dicha resolución para demostrar tal aseveración.

\footnotetext{
4 Por su parte, la Sala de lo Contencioso Administrativo ha adoptado el mismo criterio (véase Sentencia Definitiva referencia 28-H-95 del 30-05-1997).

5 Antequera Vinagre, J.M. Derecho Sanitario, Manuales de Dirección Médica y Gestón Clínica. España: Editorial Ediciones Díaz de Santos, 2006. p 136... "El matiz fundamental se encuentra en la relajación de dichos principios cuando se imponen sanciones de carácter disciplinario, es decir, cuando nos encontramos en el marco de las relaciones especiales de sujeción."

6 Cano Campos, T. "La culpabilidad y los sujetos responsables en las infracciones de tráfico". DA Revista de Documentación Administrativa Número 284-285. Las Sanciones de Tráfico, 2009: 84. p. 84.

7 Huergo Lora, A. La Sanciones Administrativas. Madrid, España: Iustel, 2007. p. 378.

8 Por ello, Cano Campos concluye su idea casi en los mismos términos expuestos por Huergo Lora. "...El denominado principio de culpabilidad constituye así otra de las exigencias constitucionales a que debe de adecuarse el Derecho administrativo sancionador, pero no por una traslación sin más del Derecho penal sino porque sus manifestaciones o exigencias derivan directamente del concepto de sanción propio de una Estado Social y Democrático de Derecho". Cano Campos, T. "La culpabilidad y los sujetos responsables en las infracciones de tráfico". Óp. Cit.... p. 84.
} 
Dentro de los argumentos de la resolución, el primero es el hallazgo de la unidad ontológica entre delito e infracción tributaria $3 / 4$ entendida como un ilícito administrativo $3 / 4$, manifestando que ya tenía sus décadas en Europa, y especialmente en España, por medio de labor jurisprudencial, ${ }^{9}$ por lo que la Sala concluye que "se insiste en el ineludible requisito de tener presente, en la creación de las normas relativas a las infracciones y sanciones tributarias, así como en su aplicación, los principios decantados en la creación de la teoría general del delito; de entre los cuales destacamos los siguientes: (a) principio de tipicidad, (b) principio de legalidad formal, (c) prohibición de la retroactividad, (ch) interdicción de la analogía, (d) regla del "re bis in ídem", (e) principio de proporcionalidad; y especialmente, en atención al caso que nos ocupa, (f) principio de culpabilidad o voluntariedad"9.

De lo anterior, una conclusión apresurada sería entender que el principio de culpabilidad es, en definitiva, una consecuencia de la aplicación de los principios penales al Derecho Administrativo Sancionador. Sin embargo, el papel de este argumento no es el de fundamentar la exigencia de la culpabilidad en el ámbito sancionador. Más allá de eso, su papel consiste, en primer lugar, en trasladar el esquema estructural del delito hacia la infracción administrativa, y en segundo, dotar de contenido a esos principios — dada la inexistencia de una dogmática administrativa que les dé una apropiada significación — como base fundamental, para luego aplicar los matices necesarios.

Posteriormente, la Sala, luego de analizar varios puntos doctrinarios, y la situación en el derecho comparado ${ }^{10}$-especialmente en Alemania, Italia y España donde se exige el elemento subjetivo de dolo o culpa para responsabilidad administrativa-, lo que lleva la siguiente conclusión:

\begin{abstract}
Al contrastar los conceptos doctrinarios y las elaboraciones legislativas extranjeras con nuestro sistema constitucional y, específicamente para el caso subjúdice, en la determinación del ámbito de la presunción de inocencia contenida en el Artículo 12 de la Carta Magna, debe tenerse en cuenta que éste incorpora un sistema de valores -Estado de Derecho, supremacía constitucional, preeminencia de los derechos fundamentales,...cuya observancia requiere una interpretación teleológica de la Norma Fundamental. 10
\end{abstract}

Este es el argumento clave, que sirve para fundamentar el principio de culpabilidad como exigencia del concepto constitucional de sanción, en términos más precisos deviene de la Constitución misma, esto es así, dado que la Sala manifiesta que en el artículo 12 reposa el principio de «Estado de Derecho», lo que sin lugar a dudas significa que una sanción — sea penal o administrativa - solo puede imponerse previo la comprobación de su culpabilidad, es decir, a título de dolo o culpa, esto respetando su calidad de persona, y, su dignidad, por ello, solo puede sancionarse cuando se ha obrado voluntariamente en oposición a la norma, cuando ha podido determinar su conducta.

Si alguna duda quedara de lo anterior, bastará observar los restantes argumentos de la Sala para corroborar dicha tesis. Véase cómo se recurre al expediente histórico del artículo 12 de la $\mathrm{Cn}$., dado que su inspiración deviene del artículo 11 de la Declaración Universal de los Derechos Humanos. Como consecuencia, la presunción de inocencia y la culpabilidad se convierten en condiciones inherentes a la dignidad de la persona humana; $y$ al establecerlo en la $\mathrm{Cn}$., se convierte en un principio de exigencia constitucional en todas las ramas del Derecho. Siguiendo esa línea de pensamiento, la Sala examina los diversos instrumentos de derecho humanos relativos a El Salvador, ${ }^{11}$ así

9 Así, el argumento: “....La anterior doctrina ha sido ratificada sin vacilaciones por el Tribunal Constitucional español, cuando en sentencia 18/81, del ocho de junio de ese año, expresó: 'Ha de recordarse que los principios inspiradores del orden penal son de aplicación, con ciertos matices al derecho administrativo sancionador, dado que ambos son manifestaciones del ordenamiento punitivo del Estado, (...), hasta el punto de que un mismo bien jurídico puede ser protegido por técnicas administrativas o penales'".

10 Para ello, la Sala realiza una exposición de la postura de Pérez Royo: “...analizando este principio, hace hincapié en la circunstancia observada en legislaciones foráneas, relativa a la incorporación del elemento subjetivo en el campo de las Infracciones Administrativas de Alemania, del veinticuatro de mayo de mil novecientos sesenta y ocho, que en el párrafo 10, precisa que las infracciones administrativas únicamente son sancionables a título de dolo y culpa; y por otro, en Italia, la Ley número seiscientos ochenta y nueve, del veinticuatro de noviembre de mil novecientos ochenta y uno, el artículo 30. párrafo primero dispone que "en las violaciones a las cuales es aplicable una sanción administrativa cada cual es responsable de la propia acción, consciente y voluntaria, sea dolosa o culposa". Además, en España, la Ley 10/85 - Ley General Tributaria- afirma - en el Artículo 77- una concepción voluntarista de la infracción".

11 Al respecto estableció: "El reconocimiento expresa que la Comisión Redactora del proyecto de Constitución hace, de fundamentarse en la Declaración Universal de los Derechos Humanos... Autoriza a esta Sala para referirse a otros convenios relativos a la protección de los derechos humanos que El Salvador ha ratificado, y que forman parte de su ordenamiento, Artículo 144 de la Constitución. En relación con la presunción de inocencia, tales tratados se hallan formulados en los siguientes términos: (a) Declaración Americana de Derechos Humanos: 'Artículo 25.- Se presume que todo acusado es inocente, hasta que se pruebe que es culpable'; (b) Pacto Internacional de Derechos Civiles y Políticos: 'Artículo 14.2.- Toda persona acusada de un delito tiene derecho a que se presuma su inocencia mientras no se pruebe su culpabilidad conforme a la ley'; y (c) Convención Americana sobre Derechos Humanos o 'Pacto de San José': 'Artículo 8.2.- Toda persona inculpada de delito tiene derecho a que se presuma su inocencia mientras no se establezca legalmente su culpabilidad'". 
como también la opinión de la Comisión Interamericana de Derechos Humanos, ${ }^{12}$ y del Convenio Europeo de Derechos Humanos $^{13}$ por lo que llega a la conclusión, la necesaria actualización de la norma fundamental, lo que significó, al menos, tres cambios fundamentales; el primero, el vocablo delito, en sentido estricto, paso a significar "... indicativo de un ilícito o injusto típico, esto es, conducta humana que en virtud de mandato legal se haced reprochable a efecto de su sanción; incluyéndose en este concepto a las infracciones administrativas"11. Como consecuencia de ello, tanto la presunción de inocencia como el principio de culpabilidad $^{14}$ pasan al ámbito de aplicación del Derecho Administrativo Sancionador.

A este punto, los argumentos vertidos son suficientes y válidos para asegurar que el principio de culpabilidad es una exigencia directa de la Constitución, y no la consecuencia de la aplicación de los principios penales al ámbito sancionatorio administrativo. La importancia de la toma de posición en este punto es radical para determinar el ámbito de aplicación del principio de culpabilidad. Si decimos que se aplica por la sujeción a los principios penales, resultaría que la aplicación de la culpabilidad se delimitaría al ámbito sancionatorio. Por otro lado, si elegimos el fundamento constitucional, es decir, la exigencia de la Constitución por establecer un Estado constitucional de derecho que se basa en el respeto de la dignidad humana, y por ello solo debe sancionarse sobre la base de la culpabilidad, se amplía el ámbito de aplicación de la culpabilidad, a medidas incluso no sancionadoras, pero que pueden inferir en la esfera jurídica de las personas.

Es así que el fundamento de la culpabilidad, como exigencia de la Constitución, ha sido confirmado y reforzado por la Sentencia de Inconstitucionalidad 65-2007 del 20-01-2009, donde se amplía el ámbito de aplicación de la culpabilidad.

La anterior expresión debe interpretarse extensivamente en el sentido de que, si bien habla de "delito", no debe entenderse circunscrita al Derecho Procesal Penal, sino que es un auténtico principio general del debido proceso y, por ende, de aplicación a procesos de todas las materias. Inclusive, su respeto también es obligatorio en procedimientos administrativos u otro tipo de trámites, con los matices correspondientes. En virtud de ello, el principio de culpabilidad no solo constituye un límite al ius puniendi 3/4como se afirmó en la Inc. 52-2003 por las características del caso $3 / 4$, sino que en general al poder jurídico del Estado.

Con esta confirmación expresa de la Sala, no cabe duda acerca del fundamento de la culpabilidad, y mucho menos de su ámbito de aplicación, que funciona como un límite al poder jurídico del Estado. Tal postura viene de la mano con la teoría moderna, que busca aplicar la culpabilidad incluso a medida no sancionadoras, en el ámbito sancionador. ${ }^{15}$

\section{Implicaciones prácticas del principio de culpabilidad en el Derecho disciplinario}

Ahora que hemos establecido el fundamento del principio de culpabilidad, y que podemos afirmar que no existe razón alguna para disminuir esta garantía en los procesos disciplinarios de los empleados públicos, debemos explicar de manera práctica cuál es la forma en que se debe aplicar dicho principio.

En la práctica de los procedimientos disciplinarios, debe seguirse el criterio de la Sala de lo Constitucional, específicamente la Sentencia de Inconstitucionalidad ref. 52-2003 del-01-2004, en la que, estableció el contenido del principio de culpabilidad en materia penal, y que ahora ha trasladado sin mayores problemas al ámbito administrativo sancionador, en la Sentencia de Inconstitucionalidad 652007 del 20-01-2009, lo que sin duda demuestra los ínfimos límites que existen entre el Derecho Penal y el Derecho Administrativo Sancionador.

La sentencia citada establece como contenido, o elementos del principio de culpabilidad, las siguientes cuatro exigencias o subprincipios que lo configuran:

\footnotetext{
12 Opinión tomada en cuenta por la Sala: "Es conveniente acotar que la Comisión Interamericana de Derechos Humanos ha condenado —Informe Anual 1984/85- la violación de la presunción de inocencia en procesos administrativos, no obstante, que la Convención Americana parece concebir esta garantía —si nos atenemos a la literalidad-como propia de los procesos penales".

${ }^{13}$ Extracto: "Por otro lado —con propósito meramente ilustrativo— es interesante observar que el Convenio Europeo de Derechos Humanos, al regular el tópico analizado, expresa: 'Artículo 6.1.- Toda persona acusada de una infracción se presume inocente hasta que su culpabilidad haya sido legalmente declarada'".

${ }^{14}$ Por ello, establece la Sala: "Podemos asegurar entonces, sin ambages, que en materia administrativa sancionatoria es aplicable el principio nulla poena sine culpa; lo que excluye cualquier forma de responsabilidad objetiva, pues el dolo o culpa constituyen un elemento básico de la infracción tributaria".

${ }^{15}$ Huergo Lora. La Sanciones Administrativas, Óp. Cit... pp. 381-384.
} 


\subsection{La personalidad de las sanciones: que no se conciba como responsable a un sujeto por hechos ajenos}

Bajo la perspectiva del principio de culpabilidad, solo podrán ser sancionadas por hechos constitutivos de infracción administrativa las personas físicas que resulten responsables de cometerlas. ${ }^{16}$ Este es el denominado principio de personalidad de las sanciones, o de responsabilidad por el hecho propio. Lo que en definitiva quiere decir, parafraseando a Cuerda Riezu, que esta declaración de responsabilidad por los hechos propios significa que debe existir una relación de correspondencia entre la infracción administrativa y su autor, y su respectiva sanción administrativa. ${ }^{17}$ De esta manera, solo a quien realice una acción puede predicársele una infracción, y solo a quien se le impute una infracción puede adjudicársele una sanción, cualquier otra forma que quebrante dicho esquema atenta contra el principio de responsabilidad por el hecho propio, y por ende contra el de culpabilidad. En conclusión, por eso no se permite la responsabilidad sin hechos. Así la derivaciones de situaciones conexas, como la prohibición trasladar la responsabilidad a terceros por hechos de otro, como la responsabilidad solidaria, la imposibilidad de heredar la responsabilidad.

3.2 La responsabilidad por el hecho: que solo se responsabilice por hechos o conductas plenamente verificables, no por formas de ser, personalidades, apariencias, etc.

El principio de responsabilidad por el hecho significa, entre otras cosas, que el hecho se convierte en el límite del castigo estatal, de manera que, mientras no exista una acción que exteriorice una conducta que busque la producción de una infracción administrativa, no podrá el Estado castigar. ${ }^{18}$ En análogo sentido, el Derecho Penal establece un derecho penal de acto, de manera que en el Derecho Sancionador se ha seguido con esa suerte, tal como expresa Sánchez García: "Este principio inspira también la apreciación de la existencia de la infracción administrativa". ${ }^{19}$

3.3 La exigencia de dolo o culpa: que el hecho del que se derivan consecuencias sea doloso, es decir, que haya sido querido por su autor o se haya debido a su imprudencia

Esta es una de las principales garantías, ya que suprime la responsabilidad objetiva y tiene por objetivo poner de relieve el elemento subjetivo del dolo y de la culpa, de manera que nadie sea reprimido por el mero resultado. Esto tiene dos facetas; la primera, cuando se crea la norma jurídica. Es un mandato hacia el legislador para adoptar los tipos infraccionarios de manera dolosa o culposa; y la segunda, como un mandato hacia el aplicador de la ley, quien debe solo castigar si se observa el elemento subjetivo.

En elemento de la culpa no se requiere una voluntad manifiesta y directa de infringir la norma, es decir, la desaprobación jurídica no recae sobre el fin de la acción, sino sobre la forma de su realización o la elección de los medios para realizarla. La norma sanciona la culpa o imprudencia

\footnotetext{
${ }^{16}$ SCA en Sentencia definitiva ref. 94-2008 del 15-03-2013.- Tómese en cuenta que, a pesar de que la resolución menciona solo persona física, no debe entenderse en el sentido estricto de persona natural, sino también en el sentido de persona jurídica, ya que el principio de personalidad de las sanciones también es corolario de la acción de las personas jurídicas, aunque con distintos matices. Asimismo, cuando se menciona el vocablo responsable debe entenderse en el sentido de autor, es decir, la persona que exterioriza su voluntad mediante la locomoción de su cuerpo dirigida a cometer una infracción. La diferencia se realiza, ya que el término responsable puede tener diferente significados, según el área de estudio. A manera de ejemplo, en el Derecho Civil responsable es un término de carácter objetivo mediante el cual se puede trasladar sanciones a quienes no hayan cometido acción alguna, ni pueda vinculársele elemento subjetivo. Es el caso de la responsabilidad extracontractual, es decir, la responsabilidad solidaria. Para el caso, debemos entender que el concepto de autor debe ser el límite del entendimiento del responsable, ya que solo se puede hacer responsable a alguien en la medida del efecto de la comisión de una acción.

${ }^{17}$ Relación que sigue explicando el autor de la siguiente manera: "Se trata de una relación de tipo jurídico que enlaza un hecho, un individuo al que se le responsabilice de ese hecho, y, en virtud de dicha responsabilidad, una consecuencia jurídica restrictiva de derechos impuesta precisamente al mismo individuo. Constituyen una trinidad o, si se prefiere, los tres lados de un triángulo, en el que cada uno de dichos lados trae causa del otro, y que deben aparecer como tales y de manera encadenada en la sentencia condenatoria..." (Cuerda Riezu, A.R. "El principio constitucional de responsabilidad personal por el hecho propio: manifestaciones cualitativas". Anuario de Derecho Penal y Ciencias Penales, 2009. p. 187).

18 Tal como ha explicado la Sala de lo Constitucional, "... no pueden calificarse y por tanto castigarse como delito las formas de ser, personalidades o apariencias, puesto que la configuración de su responsabilidad es de difícil determinación, distinto a los hechos o conductas plenamente verificables —-principio de responsabilidad por el hecho-, y la consecuente proscripción de un derecho penal de autor". Sentencia de Inconstitucionalidad Ref. 52-2003 del -01-2004.

19 Sánchez García, T. "Derecho Penal Administrativo". Cuadernos de Derecho Judicial, Derecho Administrativo Sancionador, CGPJ, 1994. P. 373. “Es de importante trascendencia dicho principio, ya que en el Derecho Administrativo Sancionador se han castigado maneras y formas de ser, como la Ley de Policía promulgada el día 21 febrero del año 1879, contenida en la Codificación de Leyes Patrias del mismo año, donde se castigan formas de ser, como las mujeres 'holgazanas', así mismo, se prohibían los vagos, los buhoneros sin patente, los tinterillos temerarios, los rufianes y mujeres públicas, los que quieren pasar por estudiantes y no comprueben estar haciendo estudios con algún profesor, los que sin la licencia respectiva andan con imágenes de santos solicitando limosnas".
} 
para motivar que no se produzcan una lesión del deber de cuidado y para que se actué con la diligencia debida. ${ }^{20}$

Por otro lado, el dolo sí requiere voluntad. Por ello, seguiremos a la Sala de lo Penal, que ha optado por la siguiente conceptualización, estableciendo que "el dolo, por una parte, supone que debe existir en el sujeto activo del delito tanto el conocimiento como la voluntad de querer provocar la conducta negativa". ${ }^{21}$ De esta manera, el concepto de dolo tiene una significación finalista. ${ }^{22}$ Por lo que su entendimiento en el Derecho Administrativo Sancionador debe ser idéntico. Distinto es que su aplicación discrepe en ambos ámbitos, siendo mínima su intervención en el área administrativa, lo cual tampoco le resta importancia.

La noción general del dolo es: conciencia y voluntad de la realización del injusto típico. ${ }^{23}$ Estos dos son los elementos exigidos por el dolo, es decir, para poder ser establecido, salvo que pueda alegarse alguna causa de atipicidad, como el error de tipo.
En ese sentido, solo pueden sancionarse conductas una vez sean a título de dolo o culpa, sin embargo, no debe caerse en el error de aplicar todas las conductas como si todas fueran a título de negligencia o culpa, sino debe de verse la regulación de la norma, y en caso de no existir una normatividad conforme debe castigarse solo a título de dolo, lo que quiere decir que no existe la preeminencia de la culpa sobre el dolo como se predica en la doctrina española, ya que no contamos con ninguna norma que así lo califique.

Esdeadvertirqueunarecienteresolución deinconstitucionalidad ha dado el primer paso en aclarar dicha situación, y que pueda corregir el filo argumentativo con el que se ha estado resolviendo en la Sala de lo Contencioso Administrativo.

La aplicación constitucional de las sanciones administrativas únicamente es viable cuando el acto típico ha sido ejecutado con dolo o culpa; afirmación que debe delimitarse, en la medida que solo es posible sancionar un comportamiento culposo, cuando éste

\footnotetext{
${ }^{20}$ Delgado Sancho, C.D. Principios de Derecho Tributario Sancionador. Madrid: El Derecho Grupo Editorial, 2010.P. 174. Por su lado, la Sala de lo Penal ha manifestado: "...De ahí que la lesión a un bien jurídico cuyo deber de cuidado correspondía a un determinado sujeto, ocasiona la responsabilidad exclusiva de éste, en la medida que su actuación negligente la haya provocado. Es imprescindible para la calificación culposa de la conducta, que el tribunal exprese con claridad y coherencia cuales son las razones en las que apoya su juicio de culpabilidad basado en la negligencia o infracción al deber de cuidado, ya que este es precisamente el principal elemento del delito imprudente". Sala de lo Penal Sentencia Definitiva de Referencia 52-03 del 04-11-03.

${ }^{21}$ Sentencia de la Sala de lo Penal Ref. 598-CAS-2007 del 31-7-2009.

${ }^{22}$ La aclaración deviene del traslado que pueda hacerse de posturas distintas, como el concepto de dolo del causalismo, cuestión que ha pretendido Palma del Teso, pero que resulta inaplicable en nuestro contexto, y que ha sido negado, tanto en el Derecho Penal como en el Derecho Administrativo Sancionador. La autora pretende una postura mixta aprovechando ventajas del concepto de dolo en el causalismo, y del finalismo. Así que establece la estructura del dolus malus como estructura, para justificar que dolo y culpa se situarán en la categoría dogmática de la culpabilidad, es decir, en la imputabilidad, de manera que en la tipicidad solo se examinará el nexo causal de manera objetiva, y lo subjetivo en la culpabilidad, de manera que cualquier infracción podría cometerse a título de dolo o culpa. Para salvar cualquier señalamiento de objetivismo, opta por establecer que la estructura del injusto estaría compuesto por la tipicidad, antijuricidad y culpabilidad, constituyendo un bloque único, en el que ningún elemento de la infracción quedaría fuera. Sin embargo, los elementos del dolo en el causalismo constituyen un valladar para la autora, dado que se exige 1) el elemento volitivo, 2) el cognitivo o intelectual y 3) la conciencia de la antijuricidad, cuestión que debería probar la administración, lo cual la obliga a tomar una postura ecléctica, recurriendo así al concepto del dolo natural del finalismo. En este solo se exige el elemento volitivo y cognitivo o intelectual, mientras que la conciencia de la antijuricidad debe probarla el imputado. De esta manera, la autora encuentra una forma mágica, donde la estructura de la infracción administrativa vendría sustanciada por una postura causalista, situando el dolo y la culpa en la culpabilidad, convirtiéndolos en simples formas de culpabilidad, o títulos de imputación, pero que, felizmente, cambia su significación a una postura finalista, donde la voluntad y la capacidad cognitiva son suficientes para acreditar la comisión dolosa, y que, por el contrario, la conciencia de la antijuricidad deberá probarla el administrado, cuestión que solo puede ser señalada como un fraude de etiqueta, ya que sutilmente conlleva a un objetivismo solapado (véase Palma del Teso, A. El principio de culpabilidad en el Derecho Administrativo Sancionador. España: Tecnos, 1996. pp. 146-149). La crítica deviene de las consecuencias del mismo clasicismo. Tal como apunta Choclán Montalvo, el pensamiento jurídico correspondiente al positivismo científico se caracteriza por adscribir todo lo objetivo al tipo y a la antijuridicidad, y todo lo subjetivo, a la culpabilidad. Por ello, la parte externa del delito pertenece a la antijuridicidad, mientras que la parte interna pertenece íntegramente a la culpabilidad; el tipo es concebido como descripción puramente externa de la realización de la acción sin componente alguno de orden valorativo. Desde una concepción absoluta o predominantemente objetiva de la antijuridicidad, se entiende que la función de la norma jurídico-penal no es la determinación de conductas, es decir, la norma penal no es una norma imperativa, sino de valoración, por ello, el injusto reside fundamentalmente en el desvalor del resultado, en la lesión o puesta en peligro de bienes jurídicos (Choclán Montalvo, J.A. El delito culposo. El Salvador: Corte Suprema de Justicia, 2001. p. 21). Lo anterior, demuestra que un concepto causalista del elemento subjetivo, es decir, de la culpa y el dolo, hace prácticamente imposible la aplicación del principio de culpabilidad, en los términos que actualmente se entienden.

${ }^{23}$ Sánchez García, T. "Derecho Penal Administrativo". Cuadernos de Derecho Judicial, Derecho Administrativo Sancionador, CGPJ, 1994. P. 373. .ES de importante trascendencia dicho principio, ya que en el Derecho Administrativo Sancionador se han castigado maneras y formas de ser, como la Ley de Policía promulgada el día 21 febrero del año 1879, contenida en la Codificación de Leyes Patrias del mismo año, donde se castigan formas de ser, como las mujeres 'holgazanas', así mismo, se prohibían los vagos, los buhoneros sin patente, los tinterillos temerarios, los rufianes y mujeres públicas, los que quieren pasar por estudiantes y no comprueben estar haciendo estudios con algún profesor, los que sin la licencia respectiva andan con imágenes de santos solicitando limosnas".
} 
aparezca expresamente descrito (tipificado) en la ley (art. $15 \mathrm{Cn}$.), ya que la regla general implica que la sanciones administrativas serán impuestas cuando la acción u omisión del infractor haya sido realizada con dolo. ${ }^{24}$

Este pronunciamiento puede ser la piedra angular que encamine la correcta aplicación del principio de culpabilidad. Por un lado, limita y dirige a los juzgadores administrativos o judiciales a no seguir aplicando dolo o culpa como meros títulos de imputación. Por otro, puede que sea la semilla que genere nuevas legislaciones administrativas más precisas, en cuanto desarrollar tipos dolosos y culposos, respectivamente.

\subsection{La imputabilidad: que el hecho doloso o culposo sea atribuible a su autor, como producto de una motivación racional normal}

Este es el último de los elementos que configuran el principio de culpabilidad. Asimismo, constituye el elemento final que se ha de examinar en la infracción administrativa, y que generalmente suele llamársele también culpabilidad. Por lo tanto, es una categoría de la infracción administrativa, y que para su no confusión con el principio de culpabilidad se prefiere la denominación de imputabilidad o capacidad de culpabilidad. En tanto su finalidad va dirigida a determinar la capacidad de comprensión de antijuricidad de los ilícitos por parte de autor. Su significación puede ser muy variada conforme a la evolución de los sistemas penales, sin embargo, un concepto bastante acorde con la actual figura de la imputabilidad puede ser el siguiente: "Como el juicio de reproche que se dirige en contra del sujeto activo de un delito, en virtud de haber ocasionado la lesión o puesta en peligro de un bien jurídico, no obstante, que tenía otras posibilidades de actuación menos lesivas o dañinas del bien jurídico". ${ }^{25}$ Repele, por tanto, al Derecho Punitivo, la existencia de fórmulas de responsabilidad objetiva, desvinculadas de un reproche personal, formulable al autor de una acción típicamente antijurídica. ${ }^{26-27}$

\section{Conclusión}

Una vez identificamos el fundamento del principio de culpabilidad, podemos concluir que dicha garantía debe aplicarse sin ambages al ámbito administrativo sancionador, y que, por supuesto, eso incluye el derecho disciplinario. Esto por ser una exigencia directa de la Constitución; y su irradiación debe llegar a todas las ramas del Derecho, y por ello, no es posible, aunque se aplique la teoría de los matices, una disminución en su aplicación, mucho debe ignorarse. Es por ello que, aunque no se tenga una ley de procedimientos administrativos, o una ley que regule el derecho disciplinario de manera general, no admisible violar la garantía del principio de culpabilidad de los empleados públicos en los procesos disciplinarios. Eso sin perjuicio de que la ley sectorial específica regule o no el principio de culpabilidad. Independientemente de su regulación en la norma, debe de respetarse y aplicarse de manera directa al caso concreto.

\footnotetext{
24 Sentencia de Inconstitucionalidad de Ref. 110-2015 del 30-03-2016.

25 Plascencia Villanueva, R. Teoría del delito. México: Unam, 2004, pp. 158-159.

${ }^{26}$ Kunsemuller Loebenfelderp, C. Culpabilidad y pena. Santiago de Chile: Edit. Jurídica de Chile, 2001. p. 19.

${ }^{27}$ Palma del Teso establece que la expresión de culpabilidad podría llevarnos a darle un contenido penalístico del carecer en el ámbito sancionador, por ello, dice que no parece posible, ni necesario, trasladar al Derecho Sancionador Administrativo las doctrinas penalistas acerca de la culpabilidad. Ello, porque considera que la identificación de culpabilidad como reprochabilidad tiene un fundamento ético o moral, de la cual aduce es ajeno al Derecho Sancionador Administrativo, esto porque la administración no debe dirigir reproches éticos o morales al infractor, dado que la finalidad del Derecho Sancionador Administrativo es la prevención. Por eso concluye la autora que "en el Derecho Sancionador Administrativo, ... la conducta típica es culpable por la simple razón de ser atribuible a su autor a título de dolo o culpa" (Palma del Teso, A. El principio de culpabilidad en el Derecho Administrativo Sancionador. Óp. Cit... pp. 41-42). Por su lado muy crítico a esta postura de la autora, Gómez Tomillo, y Sanz Rubiales, manifiestan "...que no puede contraponerse reprochabilidad —con un contenido ético característico del Derecho penal - a prevención, finalidad característica del Derecho administrativo sancionador. En la actualidad, sin que ni siquiera entendamos precisa la cita de sentencias o autores, de forma absolutamente dominante, se estima que el Derecho penal cumple funciones exclusivamente preventivas (generales 0 especiales), por lo que la coincidencia es plena con el Derecho administrativo sancionador. En consecuencia, reproche equivale a censura, a desaprobación de la conducta, lo cual se puede determinar de acuerdo con parámetros sociales, culturales o puramente jurídicos, pero en absoluto éticos, ya que para ese último el Derecho sancionador no es competente" (Gómez Tomillo, M. y Sanz Rubiales, I. Derecho Administrativo Sancionador parte general, teoría general y práctica del Derecho Penal Administrativo. España: Thomson Reuders Aranzand, 2013. pp. 457-458).
} 
Referencias

Antequera Vinagre, J. M. (2006). Derecho sanitario, manuales de dirección médica y gestión clínica. Madrid: Ediciones Díaz de Santos.

Cámara de la $3^{\circ}$ Sección de occidente, Ahuachapán. (12 de julio de 2006) Sentencia, Ref. 72-06.

Cano Campos, T. (2009). La culpabilidad y los sujetos responsables en las infracciones de tráfico. Revista de Documentación Administrativa. 284-285.

Choclan Montalvo, J. A. (2001). El delito culposo. San Salvador: Corte Suprema de Justicia.

Choclan Montalvo, J. A. (2008). Criterios de atribución de responsabilidad en el seno de la persona jurídica en el artículo 31 bis del texto proyectado, en El anteproyecto de modificación del Código Penal. Bilbao: Universidad de Deusto.

Cuerda Riezu, A.R. (2009). El principio constitucional de responsabilidad personal por el hecho propio: manifestaciones cualitativas. Anuario de Derecho Penal y Ciencias Penales. Recuperado de https:// www.boe.es/publicaciones/anuarios_derecho/ abrir_pdf.php?id=ANU-P-2009-10015700209_ ANUARIO_DE_DERECHO_PENAL_Y_CIENCIAS _PENALES_EI_principio_constitucional_de_ responsabilidad_personal_por_el_hecho_propio:_ manifestaciones_cualitativas

Delgado Sancho, C. D. (2010). Principios de derecho tributario sancionador. Madrid: El Derecho Grupo Editorial.

Edwards, Carlos Enrique. (1995). Régimen penal y procesal penal aduanero: comentario de los artículos 860 a 1180 de la ley 22.415 con las modificaciones introducidas por leyes 23.353,24.415 y decreto 1684 /
93, delitos e infracciones aduaneras procedimientos, recursos, jurisprudencia, exposición de motivos. Buenos Aires: Astrea.

García de Enterría, E., \& Ramón Fernández, T. (2006). Curso de derecho administrativo. (V. 2). Madrid: Civitas.

Gómez Tomillo, M., \& Sanz Rubiales, I. (2013). Derecho Administrativo Sancionador parte general, teoría general y práctica del Derecho Penal Administrativo. Madrid: Thomson Reuders Aranzand.

Huergo Lora, A. (2007). La sanciones administrativas. Madrid: Lustel.

Kunsemuller Loebenfelderp, C. (2001). Culpabilidad y pena. Santiago de Chile: Jurídica de Chile.

Nieto, A. (2012). Derecho Administrativo Sancionador. Madrid: Tecnos.

Palma del Teso, A. (1996). El principio de culpabilidad en el Derecho Administrativo Sancionador. Madrid: Tecnos, 1996.

Plascencia Villanueva, R. (2004). Teoría del delito. México, D.F.: Unam.

Sánchez García, T. (1994). Derecho Penal Administrativo. Cuadernos de Derecho Judicial. CGPJ.

SCA. (15 de marzo de 2013) Sentencia definitiva ref. 94-2008.

SCA. (17 de diciembre de 1992) Sentencia de inconstitucionalidad de Ref. 3-92 (Ac) 6-92

SCA. (20 de enero de 2009) Sentencia de inconstitucionalidad 65-2007.

SCA. (20 de enero de 2009) Sentencia de inconstitucionalidad 65-2007

SCA. (30 de marzo de 2016) Sentencia de Inconstitucionalidad de ref. 110-2015

SCA. (30 de mayo de 1997) Sentencia definitiva referencia 28-H-95.

SCA. (Enero 2004) Sentencia de Inconstitucionalidad ref. 52-2003 